\title{
A BNCC E O TRAVAMENTO DO PENSAR DEVIR-ALUNO
}

\author{
Grace da Silva Felix* \\ Artur José Renda Vitorino**
}

\begin{abstract}
RESUMO: Pela filosofia da Diferença, de Gilles Deleuze, o artigo em questão tem por finalidade tensionar a relação entre a identidade aluno ubíqua no documento normativo da Base Nacional Comum Curricular e o deviraluno emergente do caos, entendido não como forma do nada, em sentido oposto, consideramos o caos como espaço de criação fugaz para conceitos e sujeitos. Propomos expor o pensamento inerte da recognição conforme Deleuze, posteriormente abordaremos o pensar como campo problemático, para então lançar luz à leitura da BNCC.
\end{abstract}

PALAVRAS-CHAVE: Pensamento; Identidade; Aprendizagem.

\section{THE BNCC AND THE HINDERING OF BECOMING-STUDENT THINKING}

\begin{abstract}
Through the philosophy of Difference, by Gilles Deleuze, the article in question is relevant to tension the relationship between the ubiquitous student identity in the normative document of the National Common Curricular Base and the becoming-student emerging from chaos, understood not as a form of nothing, in the opposite sense, we consider chaos as a space of fleeting creation for concepts and subjects. We propose to expose the inert thinking of recognition according to Deleuze, later we will approach thinking as a problematic field, to then shed light on the reading of the BNCC.
\end{abstract}

KEYWORDS: Thought; Identity; Learning.

\footnotetext{
* Pontifícia Universidade Católica de Campinas - mestranda do Programa de Pós-Graduação em Educação, financiamento Capes código de financiamento 001, Campinas, SP, Brasil. E-mail: grefelix@gmail.com Orcid: https:/ / orcid.org/0000-0002-8178-0103

** Pontifícia Universidade Católica de Campinas - Docente do Programa de Pós-Graduação em Educação, Campinas, SP, Brasil. E-mail: arturvitorino@puc-campinas.edu.br Orcid: https://orcid.org/0000-0002-8654-3182 


\section{Introdução:}

A aprendizagem é comumente associada a um processo voluntário, que demanda boa vontade e disposição do aluno; assim, o pensamento seria não mais que uma convergência de faculdades em um sujeito que anseia pela verdade e pelo conhecimento e, portanto, um indivíduo transcendente ao qual o conhecimento é imanente.

A filosofia da diferença oferece um contraponto ao sugerir um aprendiz fugaz cujas faculdades só podem ser acionadas pelo acaso de um encontro com um signo que, ao propor um enigma, estabelece o uso transcendente de suas capacidades cognitivas, despertando o pensamento para a ação involuntária de pensar.

Um aprendiz assim compreendido não cede espaço para uma identidade estabelecida previamente como propõe a proposta da Base Nacional Comum Curricular, doravante BNCC. À vista disso, propomos apresentar em linhas breves o revés da padronização e a que se destina tal intuito.

\section{Imagem dogmática do pensamento}

A função sui generis da filosofia, aos olhos de Gilles Deleuze e Félix Guattari (2010), resume-se primordialmente em criar conceitos, de onde decorre a crítica ao pensamento conceitual filosófico clássico, cujo pressuposto implícito e explícito efluem de "uma Imagem do pensamento pré-filosófica e natural, tirada do elemento puro do senso comum” (DELEUZE, 2018, p. 182).

Um conhecimento filosófico alicerçado em pressupostos infere um campo pré-filosófico de onde emergem ideias as quais a filosofia se limitaria a corroborar, de modo que todo começo filosófico permaneceria ancorado no "todo mundo sabe"; logo, não há retorno do diferente, nem ao menos um círculo que incida sobre diferenciais (DELEUZE, 2018, p. 189; DELEUZE; GUATTARI, 2010, p. 35), e sim o oposto.

\footnotetext{
De acordo com essa imagem, o pensamento está em afinidade com o verdadeiro, possui formalmente o verdadeiro e quer materialmente o verdadeiro. E é ancorada nessa imagem que cada um sabe, que se presume que cada um saiba o que significa pensar. Pouco importa, então, que a filosofia comece pelo objeto ou pelo sujeito, pelo ser ou pelo ente, enquanto o pensamento permanecer submetido a essa Imagem que já prejulga tudo, tanto a distribuição do objeto e do sujeito quanto do ser e do ente (DELEUZE, 2018, p. 182)
}

Acreditava-se que todo sujeito naturalmente pense, daí a filosofia partir da premissa que todos saibam o que significa pensar (DELEUZE, 2018, p. 181). O anseio homogeneizante do reconhecimento impulsionaria pessoas a afirmarem um suposto saber compartilhado, de onde provem a convicção da sentença complementar "ninguém pode negar"; visto que todos concordem acerca de determinado assunto e, portanto, todos possam reconhecer como verdadeiro, a negação do mesmo é improvável. A 
sutil ruptura com o postulado da recognição se faz sentir no instante em que alguém se recuse a ser representado "e que nega, não reconhece aqueles que falam em seu nome” (DELEUZE, 2018, p. 181), lança-se, desse modo, as raízes primevas da não identidade.

O senso comum robusteceria a construção da identidade do objeto via a atuação concorde de todas as faculdades que assumem os moldes de modos do pensamento no sujeito; similarmente, o bom senso trata-se da partilha uníssono do universal "É o bom senso que determina a contribuição das faculdades em cada caso, quando o senso comum traz a forma do Mesmo" (DELEUZE, 2018, p. 185) Por conseguinte o pensamento, na imagem dogmática, configura-se como unidade de funcionamento onde cada faculdade acena como uma variação do mesmo, pressupondo um sujeito constituído previamente; somado a característica unitária está a função de orientar o funcionamento na forma do Mesmo em conformidade com o modelo da recognição. O produto final na esteira da produção cognitiva é a consolidação da doxa, em virtude da tríade: senso comum, bom senso e pressupostos pré-filosóficos é que se alicerçam o universalmente conhecido.

O pensamento conformado à representação supõe a bondade, o bem e o verdadeiro, incorrendo na moralidade de instituições amplas e dominantes tais como a Igreja e o Estado, que por sua vez disciplinam o corpo social (DELEUZE, 2018, p.187).

Quando Nietszche se interroga sobre os pressupostos mais gerais da filosofia, diz serem eles essencialmente morais, pois só a Moral é capaz de nos persuadir de que o pensamento tem uma boa natureza, o pensador, uma boa vontade, e só o Bem pode fundar a suposta afinidade do pensamento com o Verdadeiro. Com efeito, quem, senão a Moral, quem, senão o Bem dá o pensamento ao verdadeiro e o verdadeiro ao pensamento...? (DELEUZE, 2018, p. 182-183).

O elemento primordial e o princípio geral da representação consiste no eu penso - o célebre cogito cartesiano -, em outras palavras, no âmago da recognição encontra-se o eu substancial que transmuta-se em parâmetro para as demais assertivas e ponto de confluência das faculdades (DELEUZE, 2018, p. 190). A diferença, na disposição cognitiva desenhada, reduz-se a ser "pensada" nos limites da identidade, oposição, analogia e semelhança, que torna possível a representação da diferença nua.

Se a filosofia teria início somente com a ausência de pressupostos objetivos e subjetivos ancorados no senso comum e no bom senso e, uma vez que os conceitos desenvolvidos por tal vertente não seriam criações, mas sim um ato de descoberta, o único caminho de subversão à passividade e inércia cognitiva acha-se em insuflar a diferença no pensamento (DELEUZE, 2018, p. 184)

A impotência do pensamento em apreender a diferença pura desconstrói o cenário harmonioso da boa vontade, instalando o caótico como “caosmo” (DELEUZE, GUATTARI, 2010, p. 245) criação inédita, de modo que para pôr em funcionamento o pensamento é imperioso uma violência externa que desnorteia aquele que é atingido de súbito. Sem ponto de apoio ou centro não há referência de reconhecimento, daí um pensamento sem imagem (DELEUZE, 2018, p.183). 
O que é primeiro no pensamento é o arrombamento, a violência, é o inimigo, e nada supõe a filosofia, tudo parte de uma misosofia. Não contemos com o pensamento para embasar a necessidade relativa do que ele pensa; contemos, ao contrário, com a contingência de um encontro com aquilo que força a pensar, a fim de erguer e estabelecer a necessidade absoluta de um ato de pensar, de uma paixão de pensar. As condições de uma verdadeira crítica e de uma verdadeira criação são as mesmas: destruição da imagem de um pensamento que pressupõe a si próprio, gênese do ato de pensar no próprio pensamento. (DELEUZE, 2018, p. 191).

O verdadeiro pensamento só age involuntariamente sem nada supor, subordina-se tão somente a um encontro fortuito que engendra o ato de pensar no interior do pensamento, ao topar com um algo que se estabelece em um entre objeto e sujeito formados posteriormente e nunca antes do encontro. O que é esse algo? É aquele de que se diz "Não sei bem o que é, mas aqui está", um algo que não pode ser visto, tocado, ouvido, e sim "só pode ser sentindo" (DELEUZE, 2018, p. 192) é no encontro com esse algo que "faz nascer a sensibilidade" (DELEUZE, 2018, p. 192). E, esse elemento nada mais é que o signo: "Portanto, é a coexistência dos contrários, a coexistência do mais e do menos num devir qualitativo ilimitado, que constitui o signo ou o ponto de partida daquilo que força a pensar” (DELEUZE, 2018, p. 194).

Uma vez diante de um signo, portador de problemas, uma faculdade é selecionada em sua forma involuntária - cabe ressaltar que o pensamento, na filosofia da diferença, trata-se de mais uma entre tantas faculdades - que é, similarmente, o uso transcendente das faculdades, isto é, a ação disjunta sem qualquer convergência ou diálogo entre elas. Nas palavras do autor: "Transcendente de modo algum significa que a faculdade se dirija a objetos situados fora do mundo, mas, ao contrário, que ela apreende no mundo o que a concerne exclusivamente e que a faz nascer para o mundo.” (DELEUZE, 2018, p. 195-196). Se na recognição o uso da memória, inteligência, imaginação, pensamento dá-se de modo coeso, na filosofia da diferença o funcionamento e articulação cognitiva ocorre de modo paradoxal (DELEUZE, 2018).

A sensibilidade desponta quando uma faculdade, selecionada ou violada, chacoalhada pela intensidade de um encontro inesperado com o signo, comunica as demais faculdades a violência com que foi coagida forçando a produção da sensibilidade (DELEUZE, 2018, p. 198). Dizer que algo saiu dos eixos é já afirmar que o bom senso já não faz agir as faculdades, não oferece movimento a elas.

O que escapa à recognição é aquilo que fomenta simultaneamente sensações contrárias, isto é, o devir que supõe os contrários (DELEUZE, 2018, p. 194), logo algo que é grande sugestiona, igualmente, o pequeno; todo uno, supõe similarmente o múltiplo, e assim sucessivamente, são os elementos que fogem ao reconhecimento.

\section{Campo problemático pela diferença}

Discorrer acerca do conhecimento e do pensamento pode sugerir uma análise da ação cerebral, entretanto, não é essa a intenção da filosofia de Gilles Deleuze “já que o pensamento não é aqui remetido 
ao lento cérebro como ao estado de coisas cientificamente determinável em que ele se limita a efetuar-se, quaisquer que sejam seu uso e sua orientação” (DELEUZE; GUATTARI, 2010, p. 47).

Solo fértil para o pensamento são os problemas e a Ideia, é o problema que evoca um conceito que possa enfim oferecer uma solução. No tocante à construção de conceitos, a filosofia da diferença parte não mais da Imagem Dogmática, longe disso, estabelece o Plano de Imanência marcado pelas velocidades infinitas (DELEUZE; GUATTARI, 2010, 45). As Ideias, por sua vez, dão base para a formação do campo problemático precisamente pela característica problematizante implicada nas mesmas (DELEUZE, 2018, p. 229).

Com efeito [...] talvez seja preciso reservar o nome de Ideias não aos puros coagitanda, mas, antes, a instâncias que vão da sensibilidade ao pensamento e do pensamento a sensibilidade, capaz de engendrar em cada caso, seguindo uma ordem que lhes pertence, o objeto-limite ou transcendente de cada faculdade (DELEUZE, 2018, p. 199).

O plano de imanência anuncia uma concepção do que vem a ser o pensar, daí ser possível inferir a ascensão de uma nova imagem do pensamento. Ante a impossibilidade do pensamento em assimilar voluntariamente o que cabe unicamente às virtualidades é que se afirma ser o plano de imanência não pensável. Pelo viés da diferença pensar é descentrar e abdicar das referências consolidadas, ora posto que só pode ser pensado o que não pode ser pensado - e novamente colocamo-nos defronte a um paradoxo - é erigido um enigma sempre anterior ao sujeito e, nesses termos, trata-se de um movimento ilimitado.

É de um campo problemático que advém o pensamento e a aprendizagem, há a possibilidade de um modo de interpretação que equipare o problemático ao hipotético incorrendo, por tal via, em erro ao tomarem os termos como sinônimos. A hipótese trata-se de uma ação da consciência e, portanto, fomenta a representação do que é o saber, à visto disso a hipótese termina por diluir o problema, ou incorporá-lo de maneira a retirar toda a potência de criação do pensamento e aprendizagem (DELEUZE, 2018, p. 263).

Não há, aqui, a intenção de estabelecer regras ou afirmar equações, fórmulas de como construir o campo problemático, e sim o compreender como fruto do acaso que, tal como um lance de dados, fornecem sempre novas combinações entre as Ideias e o conteúdo virtual, por conseguinte, o acaso difere do arbitrário e desconsidera qualquer combinação virtual prevista ou atualizada em probabilidades; afinal, é precisamente esse o caminho para a mutação do problema em hipótese (DELEUZE, 2018, p. 164).

Um falso problema é denunciado no uso indevido da Ideia, que termina por envolver a diferença na negação, metamorfoseando um problema em bipótese e encarnando o negativo. Os problemas mal colocados concernem as misturas de natureza e não as diferenças de intensidade ou de grau: "Se os termos não correspondem a 'articulações naturais', então o problema é falso, não é concernente à “própria natureza das coisas" (DELEUZE, 2012, p. 14). Destarte, a ausência de respostas ou soluções não invalida 
um problema, ora é próprio da questão elevar o problemático às últimas consequências e silenciar qualquer solução empírica (DELEUZE, 2018, p. 261).

As ideias homogeneizantes no tocante à ordem, ao ser e ao possível caracterizam a presença de um problema mal colocado, portanto, falso, daí ver como menos o que é mais, o que é múltiplo e virtual como similar ao atual, a falsidade e ilusão estabelecem relações entre coisas de naturezas díspares (Deleuze, 2012, p. 15).

Em resumo, toda vez que se pensa em termos de mais ou de menos, já foram negligenciadas diferenças de natureza entre as duas ordens ou entre os seres, entre os existentes. Por aí se vê como o primeiro tipo de falsos problemas repousa em última instância sobre o segundo: a ideia de desordem nasce de uma ideia geral de ordem, com misto mal analisado etc. E o engano mais geral do pensamento, o engano comum à ciência e à metafísica, talvez seja conceber tudo em termos de mais e de menos, e de ver apenas diferenças de grau ou diferenças de intensidade ali onde, mais profundamente, há diferenças de natureza. (DELEUZE, 2012, p. 15, grifo do autor).

Um falso problema, que incorre em ilusões no que tange à natureza da diferença - mais precisamente caracterizado por meio da presença do negativo, da ilusão e da presença do mais e do menos - acabam por refletir o problema original que instiga a uma solução em vias de se fazer (DELEUZE, 2018, p. 275), uma vez que discorrer acerca do problemático transcende o empírico sem, contudo, almejar o transcendental, de modo que o elemento fundamental que lança as bases do engendramento do problema são as Ideias.

Uma Ideia carece de ser devidamente entendida como portadora de relações diferenciais das mais variadas, cujo conteúdo dá-se na forma de virtualidades; ao atualizarem-se essas variedades de relações e distribuições de pontos singulares formam-se a materialidade fragmentada do todo coexistente virtual, a composição da Ideia ocorre pela diferenciação, enquanto a atualização dá-se por meio da diferençação que origina a fórmula diferen $\frac{c i}{c ̧}$ ação que serão melhor explicitada adiante (DELEUZE, 2018, p. 274), a realidade não se trata, portanto, da realização pré-definida virtualmente, afinal, o real difere do virtual na medida em que a atualização não se configura como a cópia de um mundo oculto e sim como a criação inédita de um conteúdo em devir constante, que apenas fulgura do caos e desaparece, é uma diferença nova que emerge no real.

As Ideias contêm todas as variedades de relações diferenciais e todas as distribuições de pontos singulares, coexistindo nas diversas ordens e "perplicadas" umas nas outras. Quando o conteúdo virtual da Ideia se atualiza, as variedades de relações se encarnam em espécies distintas e, correlativamente, os pontos singulares, que correspondem aos valores de uma variedade, se encarnam em partes distintas, características de tal ou qual espécie (DELEUZE, 2018, p. 274). 
O conteúdo virtual da Ideia, com a finalidade de alcançar a determinação, sofre a diferenciação, que por sua vez atualiza-se via a diferençação; entretanto, o conteúdo virtual não deve ser entendido como semelhante ao que é atualizado, haja visto que a diferenciação diz respeito a um todo não divisível; a diferençação, por sua vez, condiz a apenas uma parte do todo virtual (DELEUZE, 2018, p. 274; DELEUZE, 2012, p. 87-88). O problema é virtual e diferenciado, já as soluções nascem da diferençação, daí a importância do campo problemático para fomentar a diferençação "É sempre um campo problemático que condiciona uma diferençação no interior do meio em que ele se encarna." (DELEUZE, 2018, p. 274).

Ambas, diferenciação e diferençação, apresentam-se como as duas partes da diferença ou metades dessemelhantes, cuja imagem virtual do objeto não corresponde a imagem atual (DELEUZE, 2018, p. 278). Na realidade virtual os pontos singulares e as relações diferenciais coexistem, não obstante, cada qual participa de uma seção, cada linha divergente como resposta ao problema e cada qual se encarnando em uma diferençação seja de partes ou espécies, a atualização do virtual depende da diferença e da repetição, de onde procede a criação inédita tendo em vista a ausência de uma ordem previamente estabelecida e repetida (DELEUZE, 2018, p. 280).

A atualização é criação precisamente por romper com a semelhança preexistente, quando uma relação diferencial se atualiza não se sabe o que virá ganhar forma, é o imprevisível, as relações diferenciais diferem das espécies as quais se encarnam, bem como as singularidades divergem das partes orgânicas as quais se enrolam "é o problema que orienta, condiciona, engendra as soluções, mas estas não se assemelham às condições do problema.” (DELEUZE, 2018, p. 281).

A repetição vestida é o percurso da diferençação e da determinação dos pontos singulares indo de $\mathrm{A}$ até $\mathrm{B}$ e por $\mathrm{B}$ retornando a $\mathrm{A}$; todavia, não há no percurso um começo, como ocorre com a repetição nua, a repetição vestida não possui um ponto de partida que estabelece "é o percurso ou a descrição progressiva do conjunto de um campo problemático” (DELEUZE, 2018, p. 279).

Diferença e repetição compõe o pensamento como eterno-retorno do diferente, cada novo ciclo difere e rompe com o anterior, a composição das séries e o retorno das singularidades incidentes umas sobre as outras criando não o possível e sim o real, oras, o todo virtual é real sem ser atual (DELEUZE, 2018, p. 279). Como já explicado somente a diferença retorna como criação posto que não se sabe o que emergirá do virtual diferençado.

Ao contrário, a retomada das singularidades umas nas outras, a condensação das singularidades umas nas outras, tanto num mesmo problema ou numa mesma Ideia quanto de um problema a outro ou de uma Ideia a outra, define a potência extraordinária da repetição, a repetição vestida, mais profunda do que a repetição nua. A repetição é o lance das singularidades. (DELEUZE, 2018, p. 267). 
O eterno-retorno com o descentramento e violência permite apenas a presença dos simulacros, sistemas de séries heterogêneas, postas em comunicação pelo precursor sombrio, o diferenciador que simula a ilusão da semelhança é a própria ação do pensamento. No eterno retorno, no caos, há não o nada, mas sim o vazio, isso porque no caos as velocidades infinitas não cessam de formar e esmaecer objetos, ou seja, de esvaziar qualquer virtual, sem atribuir essência. O eterno retorno, ou o caos, pode ser o próprio sistema de pensamento, que de movimentos tão intensos e ferozes não comporta um sujeito substancial, que diante do impetuoso um sujeito formado seria dilacerado, daí apenas os sujeitos-larvares comportarem tal pensamento involuntário (DELEUZE, 2018, p. 159-161).

Em si mesmas, elas são vividas pelo indivíduo-embrião em seu campo de individuação. Além disso, como observava Vialleton, discípulo de Baër, elas só podem ser vividas pelo indivíduo-embrião: há 'coisas' que só o embrião pode fazer, movimentos que só ele pode empreender ou, antes, suportar [...] As proezas e o destino do embrião consistem em viver o inviável como tal e a amplitude de movimentos forçados, que quebrariam qualquer esqueleto ou romperia os ligamentos [...] E antes do embrião, tomado como suporte geral de qualidades e de partes, há o embrião como sujeito individual e paciente de dinamismos espaço-temporais, sujeito larvar (DELEUZE, 2018, p. 284).

O encontro abrupto com um signo, instante de conflito violento, embate entre um sujeito que se forma para sentir e um enigma que o força a se formar, daí não ser possível um indivíduo pronto em que esteja engessado os sentidos, um ser assim constituído sofreria não apenas a violência, mas anulação e o cindir de cada parte que o compõe, o aprendiz, à vista disso, não poderia ancorar-se em suas próprias habilidades ou confiar no uso voluntário de suas faculdades, de onde infere-se ser impossível a identidade aluno.

\section{Aprendizagem - do saber ao apreender}

Aprender concerne ao instante entre o não saber e o saber; logo, o aprendizado não se detém no saber cognitivo de tendência psicológica, não há, na perspectiva deleuziana, um saber ou conjunto de conhecimentos intrínseco ao aprendiz, por assim ser não se pode alegar conhecimento inato ou imanente ao sujeito (DELEUZE, 2018, p.223), se aprender é desvendar o enigma fulgurante, o saber, por sua vez, se opõe de seu predecessor ao limitar-se em reunir regras e soluções. $O$ aprendizado se inicia com o signo e todas as singularidades de uma Ideia provocante que suscite o pensamento como transcendente, todo aprendizado é um desenrolar de decifração (DELEUZE, 2010, p. 4; DELEUZE, 2018, p. 221).

Aprender é penetrar no universal das relações que constituem a ideia e nas singularidades que lhes correspondem. A Ideia de mar, por exemplo, como mostrava Leibniz, é um sistema de ligações ou de relações diferenciais entre partículas e de singularidades correspondentes aos graus de variação dessas relações, o conjunto do sistema encarnando-se no movimento real das ondas. Aprender a nadar é conjugar pontos notáveis de nosso corpo com os pontos singulares da Ideia objetiva para formar um campo problemático. (DELEUZE, 2018, p. 221). 
O aprendiz da diferença não se resigna em face a um problema, longe disso defronta o mesmo, seja um problema de ordem prática ou especulativa. Aprender consiste em uma ação subjetiva ante um campo problemático objetivo correspondente as Ideias, daí Gilles Deleuze afirmar que o aprender ocorre no inconsciente "dá-se no inconsciente, estabelecendo, entre a natureza e o espírito, o liame de uma cumplicidade profunda" (DELEUZE, 2018, p. 222).

É no aprendiz que as faculdades são elevadas ao uso transcendente desenhado como ser do sensivel que de conta de apreender precisamente o que só pode e deve ser sentido, donde assevera-se que aprender é, antes de qualquer outra coisa, um ato de apreender "Ele procura fazer com que nasça na sensibilidade esta segunda potência que apreende o que só pode ser sentido. [...] A partir de que signos da sensibilidade, por meio de que tesouros da memória, sob torções determinadas pelas singularidades de que Ideia será o pensamento suscitado? (DELEUZE, 2018, p. 222).

Esse ser do sensível é o único que pode apreender o signo retirando o sujeito do entorpecimento da recognição ao comunicar, por meio de um movimento brusco e imprevisível, para as demais faculdades a presença de algo ainda não visto; esse ser do sensível forma-se por intermédio da diferença presente na intensidade.

Apenas o uso transcendente permite tal acesso ao sensível, uma vez que a intensidade, encoberta pela qualidade, confunde os sentidos conscientes, daí a distorção dos sentidos ser crucial para a formação do ser capaz de apreender a intensidade (DELEUZE, 2018, p. 315), às margens da síncope, derivada da confusão momentânea pela violência do signo é que se pode aproximar do que seja a experiência em seu sentindo mais vívido. Entretanto, cautela, não é assim que se espera ocorrer com o aprendiz, a vertigem acena, tão somente, como exemplo compreensível, o sensível não é de todo explicável, sabe-se, ainda assim, que topou com um signo quando esse permite um despertar misterioso para o não visto, não ouvido, para o sensível não empírico.

O aprendiz é um sujeito que se forma de maneira fugaz, um sujeito que sente o signo e que só então inicia a caminhada de aprendizado, e somente nesse sujeito efêmero que as faculdades ganharão forma transcendente, um aprendiz é um corpo sem órgãos, ou seja, um alguém que não busca no uso voluntário de suas faculdades a resposta, só é possível considerar um devir-aluno e não um aluno estabelecido como identidade, como sujeito ao qual o pensamento e o conhecimentos seja imanente, mas sim um vir a ser constante, que surge no caos a uma velocidade infinita e desaparece, se forma para se desaparecer e fazer surgir outros devires, por isso o caos é vazio, não consegue ser preenchido por sempre estar nesse movimento de fazer e desafazer.

Por não concernir a um processo estabelecido previamente é que não se sabe como cada aluno reagirá, muito além de fomentar a apreensão de conteúdos objetivos é preciso, no viés da diferença deleuziana, o incentivo a decifração do mundo aqui e agora que cerca cada pessoa, é no campo problemático que se desenvolve o aprendizado temporal por intermédio de signos: "Nunca se sabe como 
uma pessoa aprende; mas, de qualquer forma que aprenda, é sempre por intermédio de signos, perdendo tempo, e não pela assimilação de conteúdos objetivos” (DELEUZE, 2010, p. 21).

O aprendizado é, por que não, o engendramento de uma postura de suspeita, a visão e consideração de que o mundo não está dado ou pronto, antes, consiste em um fazer-se, é preciso decifrar e assim criar ou descobrir mundos escondidos ou virtuais atualizados e diferenciados (DELEUZE, 2018, p. 25) O aluno não pode acreditar que cada discurso seja o todo e diga tudo, e sim que, cada gesto do professor, dos colegas, das pessoas e indivíduos que encontra emanam e comunicam signos.

O indício de uma aprendizagem em andamento e movida pela diferença parte da constatação de uma superação da ilusão quanto à relação sujeito e objeto, isto é, quando o aprendiz compreende que a verdade que busca não está contida no objeto que emana o signo, tampouco no sujeito que o apreende, de modo que uma possível confusão denunciará o uso disjunto das faculdades que buscam a solução do problema. Um aprendizado idiossincrático como o aqui exposto, estaria em harmonia com a Base Nacional Comum Curricular?

\section{BNCC: identidade em oposição ao devir}

A Base Nacional Comum Curricular não é um currículo, mas cabe a ela ser uma referência para a formulação dos currículos da Educação Básica que, por sua vez, se divide em três etapas: Educação Infantil, Ensino Fundamental e Ensino Médio (MACEDO, 2019, p. 42). O ensino médio foi incluído no texto oficial apenas em 2018. A interrelação entre currículo e a BNCC dá-se precisamente por serem os currículos a fonte e norte das práticas e conhecimentos a serem desenvolvidos em sala de aula (MACEDO, 2019, p. 42). O presente artigo não se deterá na análise do documento como um todo, atendo-se exclusivamente aos fundamentos pedagógicos, tendo em vista que são os mesmo a oferecem suporte para as práticas em sala e para elaboração dos currículos.

As especulações acerca da necessidade de uma Base Nacional Comum Curricular no Brasil, conforme Macedo, não compõem o rol dos temas inéditos e singulares aos tempos atuais. Já na Constituição de 1988 lançam-se as primeiras discussões no tocante à questão. Posteriormente, em 1996, com a formulação da Lei de Diretrizes e Bases da Educação Nacional no 9394/96 (LDB), os Parâmetros Curriculares Nacionais (PCNs), percorrendo as Diretrizes Curriculares Nacionais Gerais para a Educação Básica e o PNE (Plano Nacional de Educação, Lei 13.005/2014) (MACEDO, 2015, p. 892; PIASSA, 2020, p. 139).

Com o Plano Nacional da Educação e as 20 metas propostas para melhorar a educação brasileira, a Base Nacional Comum Curricular passa a ganhar destaque devido o diálogo estabelecido com a PNE, tendo em vista a referência a BNCC em 4 das 20 metas estabelecidas, cabe salientar, conforme Macedo, que as bases presentes nas metas do PNE são tão somente estratégias cuja finalidade a ser alcançada é a educação de qualidade (MACEDO, 2015, p. 893). 
No percurso legislativo percorrido ainda não havia um documento especifico que se enquadrasse como lei e prescrevesse o conteúdo mínimo comum a serem adotados por todos os currículos nacionais; assim, as iniciativas anteriores à BNCC, salvo a exceção das Diretrizes Curriculares Nacionais da Educação Básica (DCNs), não comportavam a obrigatoriedade de adesão (PIASSA, 2020, p. 139). Portanto, por essa ótica a BNCC configurasse como medida inédita.

A identidade tem solo fértil na BNCC em virtude da ubiquidade de um personagem-aluno fantasiado de todos. A universalização acena logo de início precisamente na presença do pronome indefinido no plural:

A Base Nacional Comum Curricular (BNCC) é um documento de caráter normativo que define o conjunto orgânico e progressivo de aprendizagens essenciais que todos os alunos devem desenvolver ao longo das etapas e modalidades da Educação Básica, de modo a que tenham assegurados seus direitos de aprendizagem e desenvolvimento, em conformidade com o que preceitua o Plano Nacional de Educação (PNE) (BRASIL, 2017, p. 7, grifo nosso).

Se todos devem ter as mesmas aprendizagens e atender as mesmas competências, onde está o outro que difere e é avivado por signos e singularidades díspares? Um dos temas adversos presentes na BNCC é a própria tentativa de ocultar os antagonismos sociais "hegemonizar significa universalizar uma concepção particular, o que, no entanto, não é capaz de apagar o antagonismo que é constitutivo do social” (MACEDO, 2019, p. 41).

São os conflitos estabelecidos e enfrentados que possibilitam o enfretamento da realidade e podem contribuir para a aprendizagem na relação com o outro; afinal, nas palavras de Gilles Deleuze: "Nunca se aprende fazendo como alguém, mas fazendo com alguém (DELEUZE, 2010, p. 21), ressaltando que o outro é tão incerto quanto um possível eu, donde afloram os conflitos por meio da própria diferençação. Aprender com o outro é considerar que cada ação involuntária emana signos decifráveis, mesmo os atos bruscos e imperativos, como apontado por Elizabeth Macedo (2019), não é possível educação sem alteridade, sem singularidade, considerando, similarmente, que se aprende com a tristeza e com a falta de empatia do outro, com o amor e a mentira (DELEUZE, 2010)

Conforme Zuleika Piassa (2020) argumenta, o discurso de tolerância às diferenças presente nos fundamentos pedagógicos pode incorrer em erro ao sugerir não o respeito e compreensão do diferente e da diferença e sim restringindo a um ato externo de suportar o que seja politicamente correto. Assim, os preconceitos e violências mantêm-se velados por coerção, o que torna muito mais complexa a constatação de atitudes agressivas movidas, a título de exemplo, por racismo, homofobia e misoginia (2020, p.39).

Ainda seguindo Piassa, o currículo entendido como artefato cultural em construção possibilita contemplar a tentativa de controle exercido por parte do documento, uma vez que apresenta qual o protótipo de cidadão em um ambiente regulado como a escola deve formar (PIASSA, 2020, p. 123). Para 
a autora, um currículo pós-crítico ofertaria uma abordagem ampla ao impulsionar a emancipação e reflexão acerca do poder, de modo que muito além da apreensão de conteúdos previamente estabelecidos o aprendiz se deteria em compreender e analisar as forças externas que tocam a vida cotidiana (PIASSA, 2020, p. 124).

Para a BNCC, na contramão de uma proposta baseada na filosofia da diferença tal como o aqui exposto, ganha evidência o sujeito da representação que considera, diante do objeto e de um o conceito, ter encontrado a essência dos mesmos. O documento valoriza, em oposição à filosofia da diferença de Gilles Deleuze, o saber e não a aprendizagem, o conhecimento deve ser desenvolvido por um sujeito pronto e substancialmente imutável ao qual o pensamento é imanente. Nesse sentindo o aprendiz é aquele que produz seu conhecimento dentro de um complexo de saberes universais amplamente difundidos que retornam ao senso comum e o bom senso, afinal "todo mundo sabe.” (DELEUZE, 2018, p. 256), ao passo que a Ideia, formada por singularidades e acontecimentos, não permite o engessamento do é, afinal, são devires, ou seja, não comportam ou consideram nenhuma possibilidade de essências (DELEUZE, 2018, grifo nosso).

A padronização fica em evidência logo no início do documento quanto à necessidade de desenvolver competências alinhadas com o PISA e a OCDE. Não seria, então, a tentativa de colocar em formas os educandos quando induzem a uma formação para avaliações de larga escala? $\mathrm{Na}$ perspectiva de Elizabeth Macedo (2019), há uma visão comportamental no tocante às competências da OCDE (2019, p. 50) que desembocam na mesma abordagem da BNCC. Ganha evidência o conhecimento instrumental, em outras palavras, o uso da cognição para fazeer algo expresso nos currículos por meio do que Macedo (2015; 2016) denomina de capacidades gerais ou competências: nada mais é do que a tentativa de instalar uma educação para o trabalho. A BNCC empreende a construção de um indivíduo de sucesso, promissor que, na ótica empresarial, faz alavancar a economia e a nação, isto é, trata-se de um aluno performático (MACEDO, 2019, p. 50; MACEDO, 2015, p. 899).

Ainda em concordância com Macedo as competências são exteriores aos sujeitos, ou seja, com a finalidade de ilustrar o impasse menciona duas características presentes no texto: empatia e curiosidade, a controvérsia reside na presença performática. Um aluno que não cumpra o esperado como empatia, ou não alcance o que o docente compreenda como curiosidade, termina por ser visto e classificado como falho ou incapaz, introjetando como limitação ou erro o que concerne à subjetividade de cada pessoa (MACEDO, 2019, p. 51).

2. Exercitar a curiosidade intelectual e recorrer à abordagem própria das ciências, incluindo a investigação, a reflexão, a análise crítica, a imaginação e a criatividade, para investigar causas, elaborar e testar hipóteses, formular e resolver problemas e criar soluções (inclusive tecnológicas) com base nos conhecimentos das diferentes áreas. (BRASIL, 2017, p. 9). 
As competências subjetivas, no tocante às emoções, culturas e aspectos sociais, tais como imaginação e criatividade, tornam-se ainda mais complexas visto que a internalização de uma suposta inaptidão e incapacidade atinge o que há de íntimo e distorce a própria autoimagem que cada sujeito projeta de si, é o esforço de universalizar e tornar generalizado inclusive quais emoções são as mais apropriadas (MACEDO, 2019).

Uma vez que a educação, pela ótica de Macedo, incita a construção ou desenvolvimento de subjetividades, então, propor como competência " 8 . Conhecer-se, apreciar-se e cuidar de sua saúde física e emocional, compreendendo-se na diversidade humana e reconhecendo suas emoções e as dos outros, com autocrítica e capacidade para lidar com elas." Abandona o intuito (usar outro termo aqui, como compreensão) da subjetividade ao tornar normativo e universal algo que cabe a cada indivíduo (MACEDO, 2015, p. 896).

A educação, seguindo Elizabeth Macedo (2015), como direito público subjetivo atesta ao indivíduo o direito educacional consolidado nos moldes objetivos da lei, por ser um direito que concerne a cada indivíduo em separado é que se qualifica como subjetivo; entretanto, se a lei é para todos os indivíduos que integram o corpo social não pode isentar-se de elementos universais comuns. Dando continuidade as reflexões de Macedo (2015), enquanto alguns itens universalistas podem ser contornados, tais como período de estada em sala, duração do ano letivo, etapas de escolarização expressas em anos; outros, tal como os currículos, são passíveis de adesão e fim de conflitos quando a diferença é posta para longe das propostas.

O conflito se dá na relação indivíduo-coletivo, já que o texto propõe direitos que são para todos e que, contudo, só são passíveis de desenvolvimento por serem subjetivos, em outros termos, a proposta de indivíduo desenhada na BNCC parte de um único modelo que forçosamente deve ser aderido por todo o coletivo estudantil, daí ser o um indivíduo abstrato adotado como representação geral do complexo educacional.

Um dos aspectos que chama a atenção é que tais direitos são direitos do indivíduo, ao mesmo tempo em que são postulados como de todos e para todos. São, portanto, direitos individuais e universais, apresentados como a única forma de garantir a vida democrática. Meu argumento aqui é que tal entendimento é efeito de um discurso político particular, no qual a igualdade se alicerça numa semelhança abstrata capaz de garanti-la. (MACEDO, 2015, p. 896).

Validar o universal como proposta de construção para os fundamentos pedagógicos da educação equivale a rotular cada aluno singular, em devir constante, como igual aos demais, donde excluise a diferença e o indivíduo tendo como alvo a semelhança generalizada. Para Elizabeth Macedo (2015), esse fenômeno da diluição do individual no universal decorre de uma representação política pósRevolução Francesa que abstraí a ideia de indivíduo complexo, formado por definições subjetivas sobre si mesmo, ou seja, todos as representações e pertencimentos arrogados por cada cidadão é retirado 
formando-se um modelo de cidadão ideal, que será o representante, o expresso nas leis, não é o cidadão real e singular que buscam os representantes políticos, e sim um ser idealizado ao qual todos serão moldados.

A igualdade legal busca a semelhança e por assim a inclusão de um ponto de semelhança entre a diferença domada, que dará forma a diversidade. Entretanto, a diferença pura torna-se uma presença incômoda, uma ameaça aos alicerces que mantêm as abstrações e, consequentemente, o universalismo; nessa linha, não inclui, antes exclui toda diferença que rompa com a semelhança necessária à igualdade, triunfando um estudante universal em detrimento do concreto. O estudante modelo passa ao largo de todas as contingências do que venha a ser um ser-humano.

Uma constante na BNCC é a presença do termo diversidade: alegando respeito e aceitação ao diverso, frequentemente compreende-se o termo como sinônimo de diferença; contudo, a diferença concerne às multiplicidades, porquanto a diversidade sugere, por sua vez, a universalização tendo em vista reunir pontos similares na superfície das diferenças. A diferença posta ao lado pelos documentos legais no âmbito educacional não é apenas de ordem acidental, isto é, cujas marcas são as características físicas ou derivadas dos vínculos de pertencimento, portanto, diferenças identitárias, em termos étnicos, gênero ou religião, indo além, trata-se de excluir a diferença singular, como acontecimento, isso porque passam a serem vistas na ótica do “todos como um” (MACEDO, 2015, p. 898).

Os alunos são comparados a um modelo previamente estabelecido, pessoas reais e complexas são postas diante de um personagem abstrato. Conforme Macedo os indivíduos que a BNCC, em colaboração e alinhamento com a OCDE, desenha destinam-se a uma sociedade estável que abstraí todos os atributos concretos do ser humano, ou seja, o controle do currículo passa ao largo da imprevisibilidade da sala de aula.

A comparação requer, e produz para existir, um genérico do sujeito, um nome sem face, o aluno competente (ou não). Com isso, ela torna a educação impossível, posto que não há educação - em si uma relação intersubjetiva - sem alteridade, sem o sujeito singular capaz de, e nem sempre, ser feliz, criativo, ter empatia, cooperar, amar. A OCDE vem tentando nos convencer de que não é possível fazer política pública de qualidade sem lançar mão das comparações. Estamos talvez diante de um impasse porque sabemos, há muito, que não é possível fazer educação (integral) sem gente de corpo e alma. (MACEDO, 2019, p. 52).

Os países com melhor ranqueamento no Pisa, de acordo com Macedo, são precisamente países em que não há currículo comum, isto é, não há a presença de uma base. Países como a Finlândia demonstram que o investimento em uma boa educação consiste em cultura, formação qualificada de professores e a liberdade de ação dos mesmos.

Para Macedo, a única base necessária é que tange a formação do professor, estabelecida como prioridade, em que não seja necessário o desvario em adotar inúmeras aulas e escolas, e assim haja tempo 
para que o educador se dedique ao aperfeiçoamento; uma base que valorize a formação física do alunado, saúde, saneamento e cultura, infraestrutura de qualidade e que comporte a quantidade de alunos que abriga (2019, p. 54).

\section{Conclusão}

A diferença opõe-se ao universal e nasce da renúncia ao racionalismo instrumental. $\mathrm{Na}$ filosofia de Gilles Deleuze, o conceito ganha novos contornos traçando um quadro de descentramento ao por fim à identidade sujeito-objeto, estabelecendo os paradoxos e devires. Os signos, portadores de um enigma, aludindo a um mundo empírico transcendente permeado de singulares virtuais capazes de gerar um campo problemático em que problemas e soluções fomentem um aprendizado temporal e sui generis.

A identidade presente na BNCC mostra-se através da universalização e padronização, criando um aluno isolado do real. À vista disso o ser do sensível (devir constante), que se forma diante de um problema diferenciado, como devir-aluno refulgente do caos, perde espaço e valor ao abarcar tão somente a versão reduzida da representação que se apoia na imagem dogmática e postulada da filosofia.

As competências e fundamentos pedagógicos da Base Nacional Comum Curricular sobrepesa a inculcação performática (MACEDO, 2019), ao abranger domínios subjetivos e emocionais, de sorte que se negar a ser representado como criativo, por exemplo, aos moldes previstos, introjeta a inaptidão e não há consciência de singularidade; destarte, que a criação de conceitos permanece inalcançável ante a letargia do pensamento.

\section{BIBLIOGRAFIA:}

BRASIL. Base Nacional Comum Curricular. Brasília: MEC, 2017.

DELEUZE, Gilles. Empirismo e Subjetividade. Trad: Luiz B. L. Orlandi. Coleção TRANS. Rio de Janeiro: Ed. 34, 1953.

DELEUZE, Gilles. Proust e Os Signos. Trad: A. C. Piquet e R. Machado. 2 ed. Rio de Janeiro: Forense Universitária, 2010.

DELEUZE, Gilles. Bergsonismo. Trad: Luiz B. L. Orlandi. São Paulo: Editora 34, 2012.

DELEUZE, Gilles. Diferença e Repetição. Trad: Luiz Orlandi e Roberto Machado. Rio de Janeiro: Paz \& Terra, 2018.

DELEUZE, Gilles; GUATTARI, Félix. O que é filosofia? Trad: Bento Prado Jr e Alberto Alonso Muñoz. São Paulo: Editora 34, 2010. 
MACEDO, Elizabeth. Base nacional comum para currículos: direitos de aprendizagem e desenvolvimento para quem? Educação e Sociedade. Campinas, v. 36, n. 133, p. 891-908, out./dez. 2015.

MACEDO, Elizabeth. A Base Nacional Curricular Comum: A falsa oposição entre conhecimento para fazer algo e conhecimento em si. Educação em Revista. Belo Horizonte, v. 32, n. 02, p. 45-67, abr./jun. 2016.

MACEDO, Elizabeth. Fazendo a Base virar realidade: competências e o germe da comparação. Revista Retratos da Escola, Brasília, v. 13, n. 25, p. 39-58, jan./mai. 2019.

PIASSA, Zuleika Aparecida Claro. O conceito de diferença no currículo escolar: uma reflexão filosófica sobre os fundamentos pedagógicos da BNCC. Tese de Doutorado. Universidade Estadual Paulista (Unesp). Faculdade de Filosofia e Ciências. Marília. 2020. 